\title{
Influence of Cement Dust Exposure on Indicators of Hepatic Function in Male Cement Handlers in Ekpoma, Nigeria
}

\author{
Oloruntoba O. Festus ${ }^{1}\left(\mathbb{D}\right.$, Solomon O. Agbebaku $2{ }^{(\mathbb{D}}$, Blessing O. Idonije ${ }^{3}(\mathbb{D})$, Olarewaju M. Oluba ${ }^{4 *}$ \\ 1 Department of Medical Laboratory Science, Faculty of Basic Medical Sciences, Ambrose Alli University, Ekpoma, Nigeria \\ ${ }^{2}$ Department of Chemical Pathology, Faculty of Basic Medical Sciences, Ambrose Alli University, Ekpoma, Nigeria \\ ${ }^{3}$ Department of Medical Biochemistry, Faculty of Basic Medical Sciences, Ambrose Alli University, Ekpoma, Nigeria \\ ${ }^{4}$ Department of Biochemistry, College of Pure and Applied Sciences, Landmark University, Omu-Aran, Nigeria \\ * Corresponding author: Olarewaju Michael Oluba E-mail: oluba.olarewaju@Imu.edu.ng ORCID: 0000-0002-5107-6959 \\ Received: 28 July 2020 Accepted: 1 January 2021
}

\begin{abstract}
Background: The rising cases of cancer and associated mobidity and mortality are indirectly linked to occupational health hazards especially in developing cases. This is further comounded by low level of compliance to safety health measures among factory workers. Ignorance and low-level of awareness on the associated health-implication of occupational risk exposure have been implicated in this regard.

Methods: The present study was carried out to evaluate the effect of cement dust exposure on selected liver function parameters in cement handlers at Ekpoma, Nigeria. A total of 114 subjects comprising 57 with history of exposure to cement dust by means of their occupation or by means of livelihood for at least one (1) year, designated as cement handlers ( $\mathrm{CH}$ ) and another 57 non-cement handlers designated as control (CT). Blood sample was collected from the anti-cubital fossa vein of each participant by venipuncture first thing in the morning before the commencement of daily activity into lithium heparin anticoagulant bottles. Plasma bilirubin (conjugated, unconjugated and total) as well as AST, ALT, ALP activities were determined using standard colorimetric methods.

Results: Bilirubin levels were altered significantly $(p<0.05)$, while ALT activity was significantly decreased $(p<0.05)$ in $\mathrm{CH}$ compared CT. AST and ALP activities were not significantly altered.

Conclusion: The results presented in this study showed that exposure to cement dust led to markedly increased level of some liver function parameters in cement handlers. This is indicative of a compromised liver function due to hepatotoxicity.
\end{abstract}

Keywords: cement dust, liver function, toxicity, hepatotoxicity

\section{INTRODUCTION}

Exposure to cement dust has been implicated as the major cause of silicosis and lung cancer. Individual involved either directly or indirectly in activities such as shearing, crushing, breaking or drilling of silica-based materials including concrete, tile, and stone in addition to building and construction workers are major culprits in this regard [1-3].

○ 2021 by the authors; licensee EJMETS by Bastas, UK. This article is an open access article distributed under the terms and conditions of the Creative Commons Attribution License (http://creativecommons.org/licenses/by/4.0/). 
Majority of factory workers in Nigeria and in other developing countries are ignorant of the need for certain precautionary measures required to safeguard their health due to ignorance and illiteracy. Most often than not they are hired without necessary prerequisite training and mobilized to work site with or without personal protective equipment [4]. Thus, knowledge and awareness about occupational hazards among factory workers in Nigeria is grossly inadequate. Thus, how working in highly dusty environments affects health and safety is a serious concern [5].

Cement dust has been implicated in pulmonary impairment, pneumoconiosis, respiratory distress and cancers of the lung and colon [5-7]. Reports from experimental studies have shown that the introduction of cement dust into systemic circulation may cause perturbations in the different tissues including liver, lung, heart, spleen, bone, muscles and hairs and ultimately affect their micro-structure and physiological performance. When cement dust is inhaled its major constituent, silica, react with water and is converted to silanol. This reaction enhances its solubility hence its absorption rate through biological membranes. This reactive product of cement dust reacts with lung cells and other cellular membranes, leading to lipid peroxidation that damages the membrane components thus compromising its integrity. Alveolar macrophages are thus stimulated, thus the production of reactive oxygen species (ROS) culminating ultimately in a condition of oxidative stress.

The oxidative stress that results is due to the overwhelming production of ROS over the cellular antioxidant defense system [2,8-10]. The loss in membrane integrity due to lipid peroxidation has been implicated in leakage of vital cellular components including enzymes into the plasma. Plasma levels of these enzymes often serve as vital diagnostic markers to indicate the level of damages to these tissues. Thus, an increase in plasma concentration or activities of certain hepatic function parameters could provide a clue to early diagnosis of organ failure due to uncontrolled exposure to cement dust. The present study was therefore designed to evaluate plasma levels of selected liver function parameters in male cement-based subjects in Ekpoma, Edo State, Nigeria. It is envisaged that data generated from this study will provide further justifications for the provision of adequate protective gadgets to cement handlers.

\section{MATERIALS AND METHODS}

\section{Sample Population}

This is a descriptive study involving two groups. Questionnaires were administered to collect information on demography and medical histories. Subjects with symptoms of respiratory distress, infection or having any form of malignant disease and those under any special medical treatment were excluded. Subjects that have been exposed to cement dust by means of their occupation or by means of livelihood for less than one (1) year were not recruited for this study. Only subjects that have been exposed to cement dust by means of their occupation or by means of livelihood for at least one (1) year were recruited for this study. A total of 114 subjects comprising 57 male adults having a history of daily exposure to cement dust and another 57 male adults who are employees of Ambrose Alli University, Ekpoma (Nigeria) with no history of daily exposure to cement dust were recruited for the study.

\section{Sample Collection}

The study was carried out within Six (6) months (March September, 2016). Blood samples (5 mL) were collected from the study participants thrice weekly (Mondays, Wednesdays and Fridays). The blood sample was collected from the anticubital fossa vein of each participant by venipuncture first thing in the morning before the commencement of daily activity. The blood was dispensed into lithium heparin anticoagulant containers and mixed gently. The blood samples were centrifuged at $3000 \mathrm{rpm}$ for $3 \mathrm{~min}$. The plasma was separated into new, clean, dry plain containers and stored frozen until analysed required for further analysis.

\section{Biochemical Analysis}

Conjugated bilirubin, unconjugated bilirubin and total bilirubin concentrations were estimated according to the method of Weber and Schalm [11]. Aspartate aminotransferase and alanine aminotransferase activities were determined according to the procedure described by Wilkinson et al. [12]. Alkaline phosphatase (ALP) activity was estimated using the method of Klein et al. [13].

\section{Ethical Consideration}

Approval for the study was granted by the Research and Ethics Committee of Ambrose Alli University, Ekpoma, Edo State, Nigeria (AAU/REC-19/05). Enrolment for the study involved aggressive awareness to educate would be participant on the focus of the study and what was expected from each participant was carried out through radio jingles, 


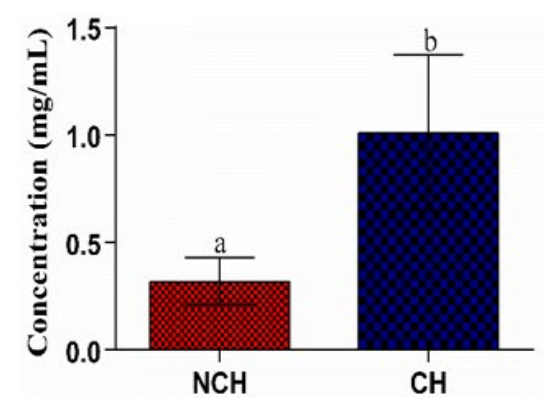

(a)

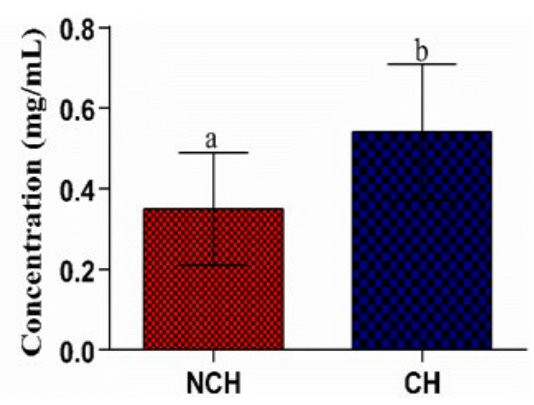

(b)

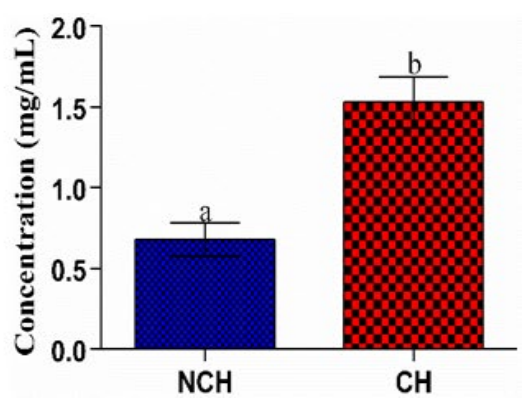

(c)

Figure 1. Plasma (a) conjugated bilirubin, (b) unconjugated bilirubin and (c) total bilirubin concentrations in non-cement handlers and cement handlers from Ekpoma, Nigeria. Values are mean \pm SEM of 57 determinations. Bars carrying different alphabets are significant $(p$ $<0.05)$. Note: $\mathrm{NCH}$, non-cement handler; $\mathrm{CH}$, cement handler

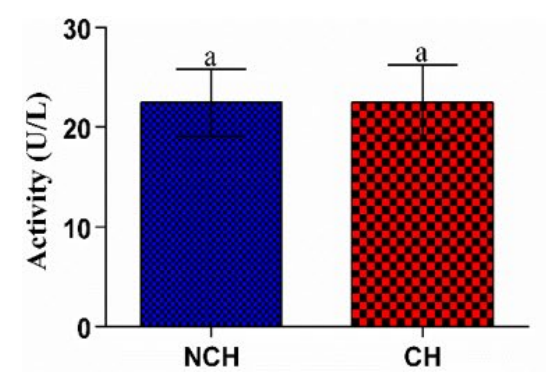

(a)

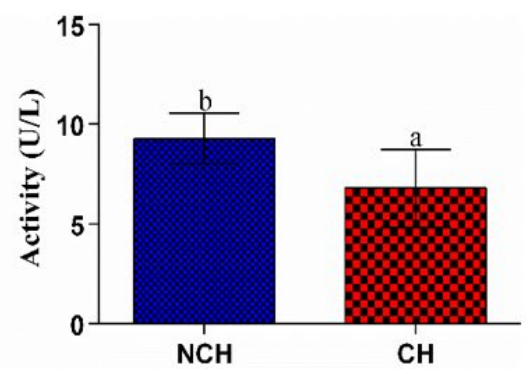

(b)

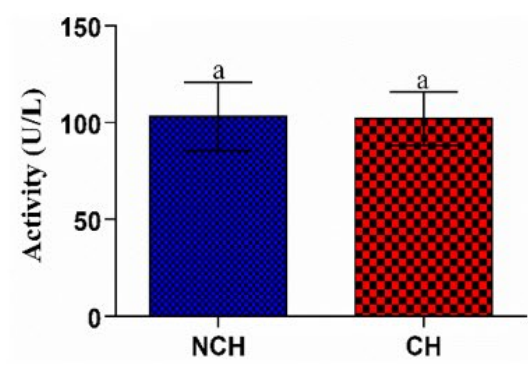

(c)

Figure 2. Plasma (a) AST (b) ALT and (c) ALP activities in non-cement handlers and cement handlers from Ekpoma, Nigeria. Values are mean \pm SEM of 57 determinations. Bars carrying different alphabets are significant $(p<0.05)$. Note: $\mathrm{NCH}$, non-cement handler; $\mathrm{CH}$, cement handler

posters and office to office campaigns. Subjects that met the inclusion criteria gave a written signed informed consent.

\section{Statistical Analysis}

Data are presented as means \pm SEM of 57 determinations. Difference between means were compared using student's t-test. $P$ value $<0.05$ was considered significant.

\section{RESULTS}

As shown in Figure 1a, mean conjugated bilirubin concentration was significantly $(p<0.05)$ higher in cement handlers $(1.01 \pm 0.36 \mathrm{mg} / \mathrm{dL})$ compared to the non-cement handlers $(0.32 \pm 0.11 \mathrm{mg} / \mathrm{dL}$ ) (Figure 1a). Unconjugated bilirubin concentration was observed to be significantly ( $p<$ $0.05)$ higher in cement handlers $(0.54 \pm 0.17 \mathrm{mg} / \mathrm{dL})$ when compared to non-cement handlers $(0.35 \pm 0.14 \mathrm{mg} / \mathrm{dL})$ (Figure 1b). Non-cement handlers had a significantly ( $p<$ $0.05)$ lower total bilirubin level $(0.68 \pm 0.10 \mathrm{mg} / \mathrm{dL})$ when compared with cement handlers $(1.53 \pm 0.16 \mathrm{mg} / \mathrm{dL}$ ) (Figure 1c).

Aspartate aminotransferase (AST) activity between noncement handlers $(22.47 \pm 3.37 \mathrm{IU} / \mathrm{L})$ and cement handlers $(22.47 \pm 3.8 \mathrm{IU} / \mathrm{L})$ was not significantly different statistically (Figure 2a). There was a significantly $(p<0.05)$ higher ALT activity in non-cement handlers $(9.28 \pm 1.28 \mathrm{IU} / \mathrm{L})$ compared to cement handlers (6.79 $\pm 1.94 \mathrm{IU} / \mathrm{L})$ (Figure 2b). Alkaline phosphatase (ALP) activity was not significantly changed between cement handlers (102.03 $\pm 13.79 \mathrm{IU} / \mathrm{L})$ and noncement handlers (103.09 $\pm 17.56 \mathrm{IU} / \mathrm{L})$ (Figure 2c).

Changes in plasma bilirubin (conjugated, unconjugated and total) concentration and plasma ALT, AST and ALP activities is presented in Table 1. Plasma bilirubin (conjugated and total) levels were increased significantly $(p<0.05)$ in cement handlers having 1 - 20 years exposure compared to those with 21 - 40 years exposure. Unconjugated bilirubin was highest in cement handlers with $16-20$ years exposure to cement dust. Cement handlers with $1-15$ years exposure had significantly $(p<0.05)$ higher unconjugated bilirubin level compared to those having $21-40$ years of exposure to cement dust. Plasma ALT activity was significantly $(p<0.05)$ higher in cement handlers with $1-20$ years of exposure to cement dust compared with those having 21 - 40 years exposure to cement dust. However, AST and ALP activities were not statistically changed in cement handlers with different durations of exposure.

\section{DISCUSSION}

Data generated from this study showed increased plasma concentrations of total, conjugated and unconjugated bilirubin in male cement handlers relative to non-cement 
Table 1. Changes in plasma bilirubin and liver enzymes based on the duration of exposure to cement dust

\begin{tabular}{|c|c|c|c|c|c|c|c|}
\hline \multirow{2}{*}{ Parameters } & \multicolumn{7}{|c|}{ Duration of exposure (years) } \\
\cline { 2 - 7 } & $\mathbf{1 - 5}$ & $\mathbf{6 - 1 0}$ & $\mathbf{1 1 - 1 5}$ & $\mathbf{1 6 - 2 0}$ & $\mathbf{2 1 - 4 0}$ & $\mathbf{~} \mathbf{- 1 5}$ & $\boldsymbol{P}$ value \\
\cline { 2 - 7 } & $\mathbf{n = 2 8}$ & $\mathbf{n = 8}$ & $\mathbf{n = 6}$ & $\mathbf{n = 3}$ & $\mathbf{n = 1 2}$ & \\
\hline $\begin{array}{c}\text { Conjugated bilirubin } \\
(\mathrm{mg} / \mathrm{dL})\end{array}$ & $0.98 \pm 0.4^{* *}$ & $1.16 \pm 0.4^{* *}$ & $1.20 \pm 0.4^{* *}$ & $0.96 \pm 0.0^{* *}$ & $0.72 \pm 0.4^{*}$ & 4.319 & 0.003 \\
\hline $\begin{array}{c}\text { Unconjugated bilirubin } \\
(\mathrm{mg} / \mathrm{dL})\end{array}$ & $0.55 \pm 0.4^{* *}$ & $0.60 \pm 0.2^{* *}$ & $0.60 \pm 0.3^{* *}$ & $1.08 \pm 0.5^{* * *}$ & $0.30 \pm 0.1^{*}$ & 8.349 & 0.00 \\
\hline Total bilirubin (mg/dL) & $1.70 \pm 0.7^{* *}$ & $1.76 \pm 0.5^{* *}$ & $1.80 \pm 0.4^{* *}$ & $1.80 \pm 0.5^{* *}$ & $1.26 \pm 0.3^{*}$ & 2.810 & 0.031 \\
\hline ALT (U/L) & $26.64 \pm 15.3^{* *}$ & $21.46 \pm 6.4^{* *}$ & $23.00 \pm 4.4^{* *}$ & $21.33 \pm 2.0^{* *}$ & $15.67 \pm 9.1^{*}$ & 2.315 & 0.044 \\
\hline AST (U/L) & $7.36 \pm 4.7$ & $7.46 \pm 2.5$ & $6.33 \pm 3.1$ & $5.00 \pm 3.7$ & $5.67 \pm 2.4$ & 1.448 & 0.226 \\
\hline ALP (U/L) & $96.46 \pm 33.5$ & $96.00 \pm 42.6$ & $110.67 \pm 33.7$ & $113.33 \pm 42.9$ & $106.25 \pm 21.4$ & 0.933 & 0.449 \\
\hline
\end{tabular}

Values are mean \pm standard deviation; Values carrying different superscripts are significant at $p<0.05$. Note: AST, aspartate aminotransferase; ALT, alanine aminotransferase; ALP, alkaline phosphatase

handlers. This observation is in agreement with the findings of Richard et al. [14] who reported an increase in the level of total and conjugated bilirubin in cement handlers. Similarly, Krishna et al. [15], also reported a significant increase in plasma bilirubin level of cement handlers. However, our results contradict the findings of Ashwini et al. [16] who reported that there was no difference in total and conjugated bilirubin of cement handlers compared with non-cement handlers. Mojiminiyi et al. [17], had also reported a general decrease in plasma total and conjugated bilirubin levels of cement factory workers compared with those of the control subjects.

The present study also showed a higher plasma levels of conjugated, unconjugated and total bilirubin in cement handler with exposure level in the range of 1 to 20 years compared to those having over 20 years of exposure. This suggests that long-term or chronic exposure to cement dust for the first fifteen (15) years have deleterious effects on the liver. The reason for this is not known. The observed decrease in plasma bilirubin concentration in workers with longer years of exposure (21 to 40 years) could have arisen as a result of adaptive immune response over the years.

Results from this study showed that plasma ALT activity was higher in non-cement handlers than in cement handlers exposed to cement dust while AST and ALP activities were similar for both groups. This finding is contrary to the reports of the study carried out by Egbe et al. [14], and AI Salhen [18] who reported a significant increase in the AST, ALT and ALP activities in cement handlers. ALT is of value as it indicates the existence of liver diseases, as this enzyme is present in large quantities in the liver. It increases in serum when cellular degeneration or destruction occurs in this organ [1921]. This finding is in agreement with similar findings of decreased plasma liver enzymes' activities in cement handlers by Mojiminiyi et al. [17] who discovered a general decrease in liver enzymes activity in cement handlers, with only the AST and ALP activities reported to have been reduced significantly. Higher plasma ALT and AST activities in cement handlers have also been reported by Malekirad et al. [22] and Al Salhen [23].

In this study, plasma ALT but not AST and ALP activity was consistently higher with increasing duration of exposure to cement dust till 20 years after which it became reduced. AST activity have been established to be elevated from birth, and generally decreases into adulthood and then increases slightly in older adults [24]. This reduction in liver enzymes activities after longer years than 20 may be as a result of the fact that most of the cement handlers tend to lessen the frequency of involvement with cement as they grow older, and their natural strength abates. The elevation of ALT levels tends to normalize over the course of several weeks after discontinuation of the contaminant or pollutant. Sometimes, asymptomatic liver enzymes test abnormalities resolve despite continued exposure to a contaminant or pollutant, a phenomenon referred to as adaptation [25].

\section{CONCLUSION}

In conclusion, results presented in this study showed that exposure to cement dust led to markedly increased level of some liver function parameters in cement handlers. The present study was focused only on subjects having direct contact with cement dust by virtue of their occupation. Expanding the scope of the study to include subjects living within the environment where cement-based factories are located will give us a bigger picture of the menace of cement dust on humans. This is because the discharge of cement dust into the environment may have implications on locally consumed vegetable by means of bioaccumulation or portable water by means of dissolution through rainfall. This is the focus of our future study. 
Author contributions: All authors were involved in concept, design, collection of data, interpretation, writing and critically revising the article. All authors approve final version of the article.

Funding: This research received no external funding.

Declaration of interest: The authors declare no conflict of interest.

Data availability: Data generated or analysed during this study are available from the authors on request.

\section{REFERENCES}

1. Falode JA, Akinmoladun AC, Olaleye MT. Ameliorative property of Kigelia africana crude and flavonoid leaf extracts on aluminum-induced hepatotoxicity in albino rats. Comp Clin Path 2019; 28: 1495-506. (doi: 10.1007/s00580-019-03004-y).

2. Xiang P, He RW, Liu RY, Li K, Gao P, Cui XY, Li H, Liu Y, Ma LQ. Cellular responses of normal (HL-7702) and cancerous (HepG2) hepatic cells to dust extract exposure. Chemosphere 2018; 193: 1189-97. (doi: 10.1016/j.chemosphere.2017.11.123).

3. Asghari FB, Jaafari J, Yousefi $M$, Mohammadi $A A$, Dehghanzadeh R. Evaluation of water corrosion, scaling extent and heterotrophic plate count bacteria in asbestos and polyethylene pipes in drinking water distribution system. Hum Ecol Risk Assess 2018; 24: 1138 49. (doi: 10.1080/10807039.2017.1407632).

4. Choudhry RM. Behavior-based safety on construction sites: A case study. Accid Anal Prev 2014; 70: 14-23. (doi: 10.1016/j.aap.2014.03.007).

5. Ngombe LK, Nlandu RN, Ngombe DKS, llunga BK, Okitotsho SW, Sakatolo JBK, Numbi OL, Danuser B. Respiratory health of dust-exposed cement carriers in Haut-Katanga province, DR Congo. Enviro, Risque Santé 2019: 1. (doi: 10.1684/ers.2019.1372).

6. Giridharan S, Shankar S. Respiratory morbidity and ventilatory function impairment among cement factory employees. Int J Med Biomed Stud 2020; 4. (doi: 10.32553/ijmbs.v4i2.988).

7. Alshammari FD, Hommi BSH, Ahmed HGK. Assessment of Infectious and Inflammatory changes in sputum associated with cement dust. Egypt Acad J Biol Sci 2014; 6(2): 33-40. (doi: 10.21608/eajbsg.2014.16498).

8. Al-Otaibi FS, Ajarem JS, Abdel-Maksoud MA, Maodaa S, Allam AA, Al-Basher GI, Mahmoud AM. Stone quarrying induces organ dysfunction and oxidative stress in meriones libycus. Toxicol Ind Health 2018; 34: 679-92. (doi: 10.1177/0748233718781290).
9. Seder L. Increased Levels of Oxidative Stress in Human Fibroblast Lung Cell Cultures and the Loss of Mitochonndrial Function Due to Exposure to Particulate Matter from September 11, 2001. Dissertation, Montclair State University, 2018. Available at: https://digitalcommons.montclair.edu/etd/150

10. Farokhzad M, Ranjbar A, Kheiripour N, Soltanian A, Assari MJ. Potential in the diagnosis of oxidative stress biomarkers in noninvasive samples of urine and saliva and comparison with serum of persons exposed to crystalline silica. Int Arch Health Sci 2020; 7: 84-8. (doi: 10.4103/iahs.iahs_37_19).

11. Weber AP, Schalm L. Quantitative separation and determination of bilirubin and conjugated bilirubin in human serum. Cli. Chim Acta 1962; 7: 805-10. (doi: 10.1016/0009-8981(62)90063-3).

12. Wilkinson JH, Baron DN, Moss DW, Walker PG. Standardization of clinical enzyme assays: a reference method for aspartate and alanine transaminases. J Clin Pathol 1972; 25: 940. (doi: 10.1136/jcp.25.11.940).

13. Klein B, Read PA, Babson AL. Rapid method for the quantitative determination of serum alkaline phosphatase. Clin Chem 1960; 6: 269-75. (doi: 10.1093/clinchem/6.3.269).

14. Richard EE, Augusta Chinyere NA, Jeremaiah OS, Opara UCA, Henrieta EM, Ifunanya ED. Cement dust exposure and perturbations in some elements and lung and liver functions of cement factory workers. J Toxicol 2016. (doi: $10.1155 / 2016 / 6104719)$.

15. Krishna L, Sampson U, Annamala PT, Unni KM, Binukumar B, George A, Sreedharan R. Genomic Instability in Exfoliated Buccal Cells among Cement Warehouse Workers. Int J Occup Environ Med 2020; 11: 33. (doi: 10.15171/ijoem.2020.1744).

16. Ashwini S, Swathi K, Shaik HS. Effects of cement dust on hematological and liver function tests parameters. Int J Cur Pharmaceut Clin Res 2016; 6: 70-3.

17. Mojiminiyi FBO, Merenu IA, Ibrahim MTO, Njoku CH. The effects of cement dust exposure on hematological and liver function parameters of cement factory workers in Sokoto, Nigeria. Niger J Physiol Sci 2007; 23: 111-4. (doi: 10.4314/njps.v23i1-2.54945).

18. Al Salhen KS. Assessment of oxidative stress, haematological, kidney and liver function parameters of Libyan cement factory workers. J Am Sci 2014; 10: 58-65. 
19. Elagib MF, Ghandour IA, Abdel Rahman ME, et al. Influence of cement dust exposure on periodontal health of occupational workers. Toxin Reviews 2020; 1-9. (doi: 10.1080/15569543.2020.1737824).

20. Idonije BO, Nwoke EO, Festus O, Oluba OM. Plasma concentrations of kidney function indicators in malaria patients in Ekpoma, South-South Nigeria. Int J Trop Med 2011; 6(1): 4-7. Available at: https://eprints.Imu.edu.ng/ id/eprint/2389

21. Onyeneke EC, Oluba OM, Ojeaburu SI, Adeyemi O, Eriyamremu GE, Adebisi KE. Effect of soy protein on serum lipid profile and some lipid-metabolizing enzymes in cholesterol fed rats. Afr J Biotechnol 2007; 6(19). (doi: 10.5897/AJB2007.000-2355).
22. Malekirad AA, Rahzani K, Ahmadi M, Rezaei M, Abdollahi M, Shahrjerdi S, Roostaie A, Mohajerani HR, Boland Nazar NS, Torfi F, Mousavi Khaneghah A. Evaluation of oxidative stress, blood parameters, and neurocognitive status in cement factory workers. Toxin Reviews 2019; 17. (doi: 10.1080/15569543.2019.1650776).

23. Al Salhen KS. Assessment of oxidative stress, haematological, kidney and liver function parameters of Libyan cement factory workers. J Am Sci 2014; 10: 58-65.

24. Sah DP, Chaudhary S, Shakya R, Mishra AK. Occupational Accidents in Cement Industries of Nepal. J Adv Res Altern Energy, Environ Ecol 2019; 6: 22-8. (doi: 10.24321/2455.3093.201904).

25. Björnsson ES. Epidemiology, Predisposing Factors, and Outcomes of Drug-Induced Liver Injury. Clin Liver Dis 2020; 24: 1-10. 